\title{
Specific Metaphase and Interphase Detection of the Breakpoint Region in 8q24 of Burkitt Lymphoma Cells by Triple-Color Fluorescence In Situ Hybridization
}

\author{
Thomas Ried, Christoph Lengauer, Thomas Cremer, Joop Wiegant, Anton K. Raap, Mels van der Ploeg, Peter Groitl, \\ and Martin Lipp
}

Institute of Human Genetics and Anthropology, University of Heidelberg, Heidelberg, Federal Republic of Germany (T.R., C.L., T.C.); Department of Cytochemistry and Cytometry, Medical Faculty of Leiden University, Leiden, The Netherlands (J.W., A.K.R., M.v.d.P.); Institute of Biochemistry, Ludwig Maximilians University, Munich, Federal Republic of Germany (P.G., M.L.)

\begin{abstract}
Triple fluorescence in situ hybridization with a plasmid DNA library from sorted human chromosomes 8 in combination with bacteriophage clones flanking the breakpoint in 8q24 of the Burkitt lymphoma cell line $\mathrm{Jl}$ was used for the specific delineation of this breakpoint in individual tumor cells. With this approach, tumor-specific breakpoints in translocation chromosomes can be detected at all stages of the cell cycle with high specificity. Genes Chrom Concer 4:69-74 (1992).
\end{abstract}

\section{INTRODUCTION}

Specific chromosomal translocations in Burkitt's lymphoma (BL) were first demonstrated by the pioneering work of Manolov and Manolova (1972) and Zech et al. (1976). In addition to the translocation $\mathrm{t}(8 ; 14)$, which has been found in some $75 \%$ of cases, variant translocations $\mathrm{t}(2 ; 8)$ and $\mathrm{t}(8 ; 22)$ have been described (for review, see Heim and Mitelman, 1987). In all cases, one breakpoint occurs in 8q24 in the neighborhood of the $M Y C$ oncogene. The exact localization of the breakpoint, however, can vary significantly from patient to patient. In some cases breakpoints have been found as far as $320 \mathrm{~kb}$ apart from $M Y C$ (Henglein et al., 1989).

Until now most cytogenetic studies of BL patients have been limited to the evaluation of banded chromosome spreads. While isotopic in situ hybridization has provided a tool to overcome the limited resolution of classical cytogenetics in the definition of breakpoints, such studies are time consuming and cannot be performed routinely (Rappold et al., 1984). Recent advances in nonisotopic in situ hybridization (NISH) can help to overcome the limitations mentioned above (for review, see Lichter et al., 1991). Chromosome-specific repetitive probes have been used to study numerical aberrations in tumor cell nuclei from cells cultivated in vitro and from tissue sections (Cremer et al., 1988a,b; Devilee et al., 1988; Hopman et al., 1988, 1989; Emmerich et al., 1989; Walt et al., 1989; Anastasi et al., 1990; Kolluri et al., 1990). A general approach to detect structural aberrations such as translocations of specific human chromosomes in metaphase cells and interphase nuclei has been established by chromosomal in situ suppression (CISS) hybridization of DNA libraries from sorted human chromosomes (Cremer et al., 1988b; Lichter et al., 1988; Pinkel et al., 1988). Its application in interphase cytogenetics, however, can create problems of interpretation due to the more extended nature of the signals from painted chromosome domains. The construction of nested sets of DNA probes that span a chromosome region of interest has been proposed as a tool to visualize tumorspecific chromosome breakpoints at all stages of the cell cycle with high sensitivity and spatial resolution (Cremer et al., 1986). This approach has already become a helpful adjunct in tumor cytogenetics. It is of particular importance in cases when analyzable metaphase cells cannot be obtained. In particular, DNA sequences flanking breakpoints of interest have provided a new tool for interphase cytogenetics of specific chromosome translocations (Arnoldus et al., 1990; Tkachuk et al., 1990). Here, we demonstrate that triple-fluorescence in situ hybridization protocols (Nederlof et al., 1989, 1990; Wiegant et al., 1991) can be applied in metaphase and interphase BL cells to visualize chromosome 8 and the two regions flanking the breakpoint in 8q24 simultaneously in different colors with high specificity.

\section{MATERIAL AND METHODS}

\section{Cells}

Human metaphase chromosomes of a healthy male donor and of the BL cell line JI were prepared according to standard techniques. In the cell line JI, a t(2;8)

Thomas Ried's present address is Department of Human Genetics, Yale University School of Medicine, New Haven, CT 06510.

Address reprint requests to $T$. Cremer, Institut für Humangenetik und Anthropologie, Im Neuenheimer Feld 328, D-6900 Heidelberg, Federal Republic of Germany.

Received May 6, 1991; accepted July 25, 1991 


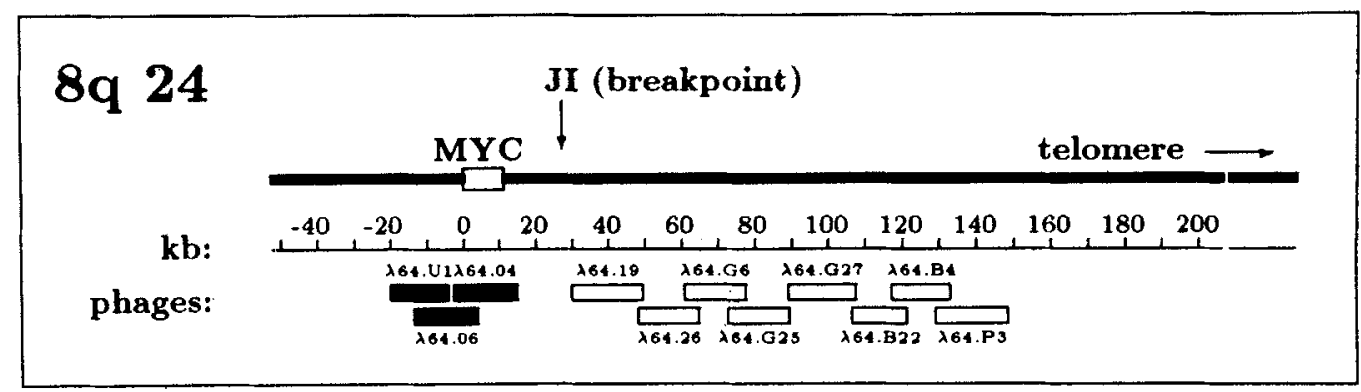

Figure 1. Scheme of human chromosome band $8 q 24$ indicating the localization of the breakpoint in the Burkitt lymphoma cell line JI in the vicinity of MYC and of II phage DNA clones used for nonisotopic in situ hybridization experiments.

(p11;q24) translocation was demonstrated by GTGbanding techniques (Bornkamm et al., 1980), and the location of the breakpoint in band 8q24 was determined by sequencing (Klobeck et al., 1987).

\section{Probe DNA}

The plasmid DNA library specific for chromosome 8 was a generous gift of Dr. J.W. Gray, Livermore Laboratory. A series of 11 bacteriophage DNA clones spanning a region of $170 \mathrm{~kb}$ in the neighborhood of MYC has been described elsewhere (Hartl and Lipp, 1987; Henglein et al., 1989) (Fig. 1). Plasmid and bacteriophage DNA was prepared using standard procedures (Maniatis et al., 1982).

\section{Probe Labelling}

Plasmid DNA prepared from the chromosome 8-specific library was labeled with bio-11-dUTP by nick translation. Bacteriophage DNA from the three clones located on the centromeric site of the translocation breakpoint in 8q24 was labeled with fluorescein11-dUTP (a generous gift of Boehringer Mannnheim). Bacteriophage DNA from the eight clones located on the telomeric site of the breakpoint was nick translated with dig-11-dUTP (Boehringer Mannheim).

\section{Triple-Color Fluorescence In Situ Hybridization}

Slides were pretreated with RNase A (Boehringer Mannheim) $(100 \mu \mathrm{g} / \mathrm{ml})$ in $2 \times \mathrm{SSC}$ for $60 \mathrm{~min}$ at $37^{\circ} \mathrm{C}$, followed by a pepsin digestion $(50 \mu \mathrm{g} / \mathrm{ml})$ in $0.01 \mathrm{M}$ $\mathrm{HCl}$ for $10 \mathrm{~min}$ at $37^{\circ} \mathrm{C}$ and a postfixation step in $1 \%$ acid-free formaldehyde in phosphate-buffered saline (PBS) $/ \mathrm{MgCl}_{2}$ for $10 \mathrm{~min}$ at room temperature. Then, $150 \mathrm{ng}$ of biotinylated chromosome 8 library, $40 \mathrm{ng}$ of pooled bacteriophage DNA from the three fluorescein isothiocyanate (FITC)-labeled clones located at the $5^{\prime}$ site of the breakpoint in JI, and $60 \mathrm{ng}$ of pooled bacteriophage DNA from the eight digoxigenin-labeled clones located at the $3^{\prime}$ site of the JI breakpoint (compare Fig. 1) were dissolved in 50\% formamide, $10 \%$ dextran sulfate, $2 \times \mathrm{SSC}$, and $50 \mathrm{mM}$ phosphate buffer with $40 \mu \mathrm{g}$ of human competitor DNA. Probe DNA was denatured for $5 \mathrm{~min}$ at $76^{\circ} \mathrm{C}$, quenched on ice, and allowed to preanneal for $2 \mathrm{hr}$ at $37^{\circ} \mathrm{C}$. Hybridization took place at $37^{\circ} \mathrm{C}$ for $15 \mathrm{hr}$.

\section{Immunological Detection}

Slides were washed three times in $50 \%$ formamide, $2 \times \mathrm{SSC}$ at $45^{\circ} \mathrm{C}$, followed by three washes in $0.1 \times$ $\mathrm{SSC}$ at $60^{\circ} \mathrm{C}$. Slides were preincubated for $30 \mathrm{~min}$ at $37^{\circ} \mathrm{C}$ in $4 \times \mathrm{SSC}, 5 \%$ nonfat dry milk, followed by three layers of immunological detection at $37^{\circ} \mathrm{C}$ for 30 min each. In between, the excess of antibodies was removed by three washing steps $\left(37^{\circ} \mathrm{C}, 5 \mathrm{~min}\right)$ in the buffer used for the immunological detection, adding $1 \%$ Tween 20 , but without blocking reagent or nonfat dry milk. Three subsequent steps were performed: the first layer contained avidin D-AMCA (Vector Laboratories) in $4 \times \mathrm{SSC}, 5 \%$ nonfat dry milk; the second layer, goat antiavidin biotinylated (Vector) rabbit anti-FITC (Dako-Patts) and mouse antidigoxin (Sigma); and the third layer, avidin D-AMCA, goat antirabbit FITC (Sigma), and rabbit antimouse TRITC (Sigma) in combination. The buffer used for the two last steps contained $0.1 \mathrm{M}$ Tris $\mathrm{HCl}, 0.15 \mathrm{M}$ $\mathrm{NaCl}$, and $0.5 \%$ Boehringer blocking reagent. Slides were dehydrated and mounted in PBS/glycerol (1:9, $\mathrm{v} / \mathrm{v}$ ) containing $2.3 \%$ of the antifade DABCO [1,4diazabicyclo-(2,2,2)-octane] (Sigma). Microscopy was performed with a Leitz Dialux Epifluorescence microscope equipped with a $100 \mathrm{~W}$ mercury lamp. Photographs were taken on 640 ASA $3 \mathrm{M}$ color slide film. While interrupting the film transport, first the AMCA signal was exposed $(20 \mathrm{sec})$, followed by exposure of the TRITC signal $(100 \mathrm{sec})$ and the FITC signal (60 $\mathrm{sec}$ ).

\section{RESULTS}

A pool of bacteriophage DNA clones spanning a region of $170 \mathrm{~kb}$ in the neighborhood of $M Y C$ (Fig. 1) 


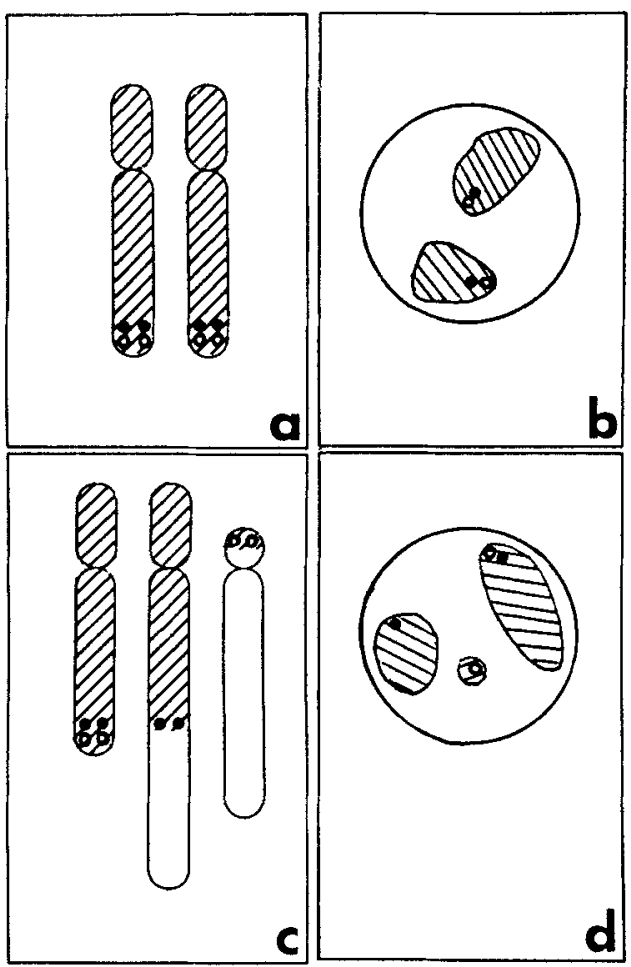

Figure 2. Experimental scheme of three-color fluorescence in situ hybridization experiments to distinguish between normal metaphase and interphase cells and tumor cells with a translocation breakpoint in $8 \mathrm{q} 24$. Hatched areas indicate chromosome material painted with a chromosome 8-specific DNA library (blue fluorescence). Black dots indicate the localization of the three phage DNA clones that map on the $5^{\prime}$ site of the $\mathrm{Jl}$ breakpoint (green fluorescence). Open circles indicate the localization of the 8 phage DNA clones that map on the 3' site of the breakpoint (red fluorescence) (compare Fig. I). a,b: Expected signals in normal metaphase spreads and interphase nuclei. c,d: Expected signals in metaphase spreads and interphase nuclei of the cell line JI with $t(2 ; 8)$.

was used for CISS hybridization to normal human lymphocyte metaphase cells. For chromosome identification, an R-banding pattern was achieved simultaneously by in situ hybridization with Alu sequences as described by Baldini and Ward (1991); see also Lichter et al. (1990). As expected, the pooled phage clones led to a strong signal on band 8q24 (see Fig. $3 a, b)$. Signals on this band were also clearly observed after CISS hybridization of single phage clones (data not shown). The cell line JI was used to demonstrate the feasibility of a triple fluorescence in situ hybrid. ization protocol for the rapid detection of specific structural chromosome aberrations in metaphase spreads and interphase nuclei of BL cells. CISS hybridization of a biotinylated plasmid DNA library from sorted chromosomes 8 was applied to paint the complete chromosomes 8 in blue color. Simultaneously, three bacteriophage DNA clones with human inserts located at the centromeric site of the breakpoint in 8q24 were labeled with fluorescein-11-dUTP and were used to paint this site in green fluorescence. Eight other clones were labeled with digoxigenin and used to delineate the telomeric site of the breakpoint in red fluorescence. A schematic presentation of the results expected with this approach in metaphase spreads and interphase nuclei of normal cells and $\Pi$ cells, respectively, is shown in Figure 2. Figure 3c-e demonstrates typical signals observed after triplecolor fluorescence in situ hybridization of a normal, diploid lymphocyte nucleus. As expected, in metaphase spreads and interphase nuclei of the BL cell line JI typical, triple-fluorescence in situ hybridization patterns were distinctly different from those distinguished in normal cells (Fig. 3f,g).

A quantitative evaluation of normal and tumor interphase nuclei is presented in Table 1 . The following criteria were developed to classify each nucleus into one of three categories, i.e. normal, tumor, and indecisive hybridization patterns.

The normal category was chosen for nuclei in which two sites with colocalized green and red signals could be detected within blue chromosome 8 domains. In most cases, two clearly separated chromosome 8 domains were observed (Fig. 3c), but nuclei exhibiting a single blue domain (due to spatially associated or overlapping chromosome 8 domains) were also included in this category. Notably, specific green and red fluorescence signals were observed in interphase nuclei either as a single spot or as a split spot, the latter possibly indicating duplication of the painted chromosome region during the cell cycle (Cremer et al., 1988b).

The tumor category was chosen for nuclei that fulfilled the following criteria: 1) a blue-painted chromosome domain with a green signal in the absence of a colocalized red one [suggesting the presence of translocation chromosome (2pter $\rightarrow 2$ p11::8q24 $\rightarrow 8$ pter)]; 2) a red signal clearly separated from this green signal (confirming the translocation); although we had expected colocalization of this red signal with a small blue domain [due to the chromosome 8 fragment in the translocation chromosome $(8 \mathrm{qter} \rightarrow 8 \mathrm{q} 24:: 2 \mathrm{p} 11 \rightarrow$ 2qter)], in our present experiments this blue signal was sometimes too weak for unequivocal detection by routine fluorescence microscopy; 3 ) colocalization of a red and a green signal in a blue-painted domain (representing the normal chromosome 8). In the large majority $(95 \%)$ of nuclei from the BL cell line JI, the blue domains of the normal chromosome 8 and the translocation chromosome (2pter $\rightarrow 2 \mathrm{p} 11:: 8 \mathrm{q} 24 \rightarrow$ 8 pter) were separated. Nuclei with a single blue domain were also included in the tumor category, pro- 

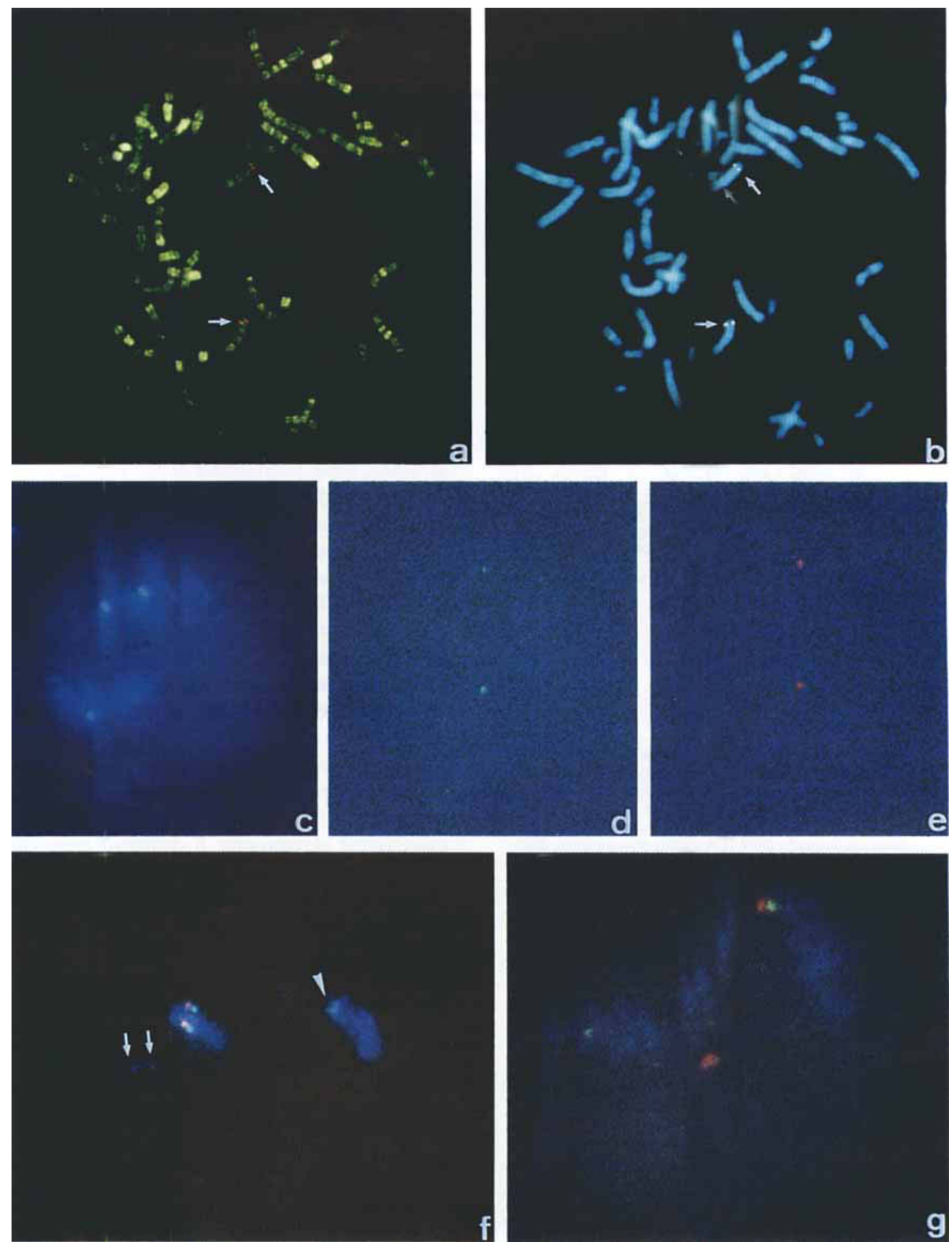

Figure 3. a,b: Localization of pooled DNA from the $1 /$ bacteriophage clones shown in Figure I on band 8q24 of a normal human lymphocyte metaphase spread. Clones were labeled with digoxigenin, and hybridization sites were detected with TRITC-conjugated antibodies (arrows). An R-type banding pattern was achieved by simultaneous hybridization with a biotinylated Alu-PCR probe detected with avidin-FITC (a) (for details see Baldini and Ward, 1991). The same metaphase spread is shown after counterstaining with DAPl in b. c-e: Normal interphase nucleus from a phytohemagglutinin (PHA)-stimulated human lymphocyte culture after triple-color in situ hybridization. c: Two chromosome 8 domains are painted in blue fluorescence. Note an intense extra signal within these domains, indicating the pericentromeric chromosome 8 heterochromatin. d: CISS hybridization of three pooled bacteriophage DNA clones that map on the $5^{\prime}$ site of the II breakpoint (compare Figs. I and 2) results in a specific green signal within each of the two chromosome 8 domains. e: Eight pooled bacteriophage clones mapping on the $3^{\prime}$ site of the Jl breakpoint are seen as two red signals. Green and red signals are colocalized. f: Metaphase cell from BL cell line Jl shows one blue-painted normal chromosome 8 with colocalized green and red spots on both chromatids (see above). The blue-painted chromosome segment with the split green spot only (arrowhead) represents the chromosome 8-derived part of the translocation chromosome (2pter $\rightarrow 2 p \mid$ I: : 8q24 $\rightarrow$ 8pter). The small blue segment bearing two red spots only (arrows) represents the chromosome 8-derived fragment of the translocation chromosome (8qter $\rightarrow 8 \mathrm{q} 24:: 2 \mathrm{p} / 1 \rightarrow 2 \mathrm{qter}$ ). Note that other chromosomes remain invisible due to the lack of a fourth color for chromosome counterstaining. g: Interphase nucleus from cell line Jl shows signals with colors corresponding to the metaphase spread shown in $\mathrm{f}$, including a blue normal chromosome 8 interphase domain with colocalized green and red spots (right), a smaller blue domain with a green spot only (8pter $\rightarrow 8 \mathrm{q} 24$; left), and a clearly separated red signal ( $3^{\prime}$ site of the breakpoint in 8q24; middle). The corresponding blue chromosome 8 fragment $(8 \mathrm{q} 24 \rightarrow 8 q$ ter) could not be seen. a,b were taken with a Zeiss Axiophot microscope equipped for epifluorescence using a CCD camera (Photometrics). The gray scale pictures were pseudocolored and merged using a software program in D.C. Ward's laboratory by Timothy Rand on an Apple Macintosh Ilcx. e- $g$ were taken with a Leitz Dialux Epifluorescence microscope on 640 ASA $3 M$ color slide film. c-e were obtained by single exposure with filter sets for AMCA (c), FITC (d), and TRITC (e); $f, g$ were obtained by triple exposure. Note that the small shift observed between the colocalized red and green signals on normal chromosomes 8 does not indicate a real difference in the physical mapping of the respective clones, but is a technical artifact due to filter changes between individual exposures. 
TABLE I. Evaluation of Triple-Color CISS Hybridization

Patterns in Normal Lymphocyte Nuclei and Burkitt's Lymphoma Jl Tumor Cell Nuclei*

\begin{tabular}{lrr}
\hline & $\mathrm{N}^{\mathrm{a}}$ & $\mathrm{jl}^{\mathrm{b}}$ \\
\hline Number of nuclei evaluated & 50 & 100 \\
Normal hybridization pattern & 45 & 0 \\
Tumor hybridization pattern & 0 & 92 \\
Indecisive hybridization pattern & 5 & 8
\end{tabular}

*For further explanation of the hybridization patterns, see text.

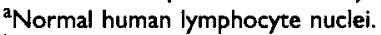

bNuclei from Burkitt lymphoma cell line Jl.

vided that in addition to a colocalized pair of green and red signals a single green signal was observed within the blue domain, while an additional red signal was found outside this domain.

Other hybridization patterns were considered indecisive. In nuclei of normal cells, a red or green signal was occasionally missing within a blue chromosome 8 domain. Occasionally, an additional small green or red spot was observed outside the blue domains. This finding can be explained by the chance localization of rare spot-like background dots, which were also found in cell-free areas of the slide. Similar observations (incomplete hybridizations or background problems) were made in BL cell nuclei. Table 1 shows that misclassifications of nuclei from normal cells as tumor nuclei and vice versa could be avoided when using the strict criteria described above.

\section{DISCUSSION}

In this study the BL cell line JI has been used as a model system to visualize the breakpoint in band $8 \mathrm{q} 24$ some $25 \mathrm{~kb}$ on the $3^{\prime}$ site of MYC. With the probe set in hand, breakpoints occurring up to some $120 \mathrm{~kb}$ on the $3^{\prime}$ site of $M Y C$ should become clearly detectable. In the future, additional, more distant probes flanking $M Y C$ on both sides could be added to discover breakpoints that presently fall outside the painted chromosomal subregion. If necessary, the precise localization of the breakpoint in an individual tumor can then be determined using individual clones contained in the probe set. In routine diagnostic settings, however, it may be sufficient to use flanking DNA probes that are several hundred kilobases away from the breakpoint site. We expect that such an approach will become highly useful for the automated image analysis of tumor-specific chromosome translocations at any stage of the cell cycle (Cremer et al., 1991).

If signals are small, as can be expected in case of individual flanking bacteriophage or cosmid clones, then the discrimination of true hybridization signals from scattered background dots can create problems. On the other hand, very extended signals, which can be created by painting the whole interphase chromosomes of interest, often lack sufficient spatial resolution in interphase nuclei (Cremer et al. 1988a). In an effort to overcome these problems, we applied a triplecolor protocol. Simultaneous painting of chromosome 8 in blue was applied to define a target area of interest within the cell nucleus. Green and red signals obtained with the 8q24-specific bacteriophage clones were consistently observed within these blue chromosome 8 domains and thus could be more easily discriminated from occasional background dots scattered within the nucleus outside the target area. A disadvantage of our present approach resulted from the fact that painting with the plasmid DNA library from sorted chromosomes 8 was not sufficient for the routine detection of the relatively small translocated fragment $8 \mathrm{q} 24 \rightarrow \mathrm{qter}$ in interphase nuclei of BL cells. Further improvements of our present approach are indicated. Nested sets of cosmid clones, YAC clones, or microlibraries obtained after microdissection of chromosome bands of interest (Lengauer et al., 1991a,b; our unpublished data) all may serve to produce multicolor painting of one or several chromosomal subregions of interest within a given cell. The position, extension, and relative signal intensity of each region may be adapted to the particular needs of each investigation. Such tools can now be established for any specific translocation breakpoint independent of whether the breakpoint itself has been cloned so far and of any knowledge of the molecular mechanism by which such a break may contribute to tumor development.

Reliable tests for the detection and follow-up studies of minimal residual disease in patients after successful treatment of hematological malignancies still present a major diagnostic problem. Polymerase chain reaction $(\mathrm{PCR})$ approaches have been introduced as a tool to detect small numbers of tumor cells with high sensitivity even in the presence of an abundance of normal cells (Lee et al., 1987; Crescenzi et al., 1988). The applicability of PCR tests, however, is limited principally to patients in whom DNA or RNA sequences can be defined that are present only in the tumor cells and not in normal cells. The scenarios discussed above for multicolor in situ hybridization in tumor cytogenetics suggest that the latter approach will have many applications that cannot easily be carried out with PCR techniques. Further studies are presently under way to test the feasibility of improved interphase cytogenetics protocols for the reliable detection of minimal residual disease. 


\section{ACKNOWLEDGMENTS}

This study was supported by a grant from the Deutsche Forschungsgemeinschaft (Cr 59/10-1). T.R. is the recipient of a postdoctoral fellowship from the Deutsche Forschungsgemeinschaft. C.L. has been supported by the Konrad-Adenauer-Stiftung. We thank Antonio Baldini and David C. Ward for help with Alu-banding experiments.

\section{REFERENCES}

Anastasi J, Le Beau MM, Vardiman JW, Westbrook CA (1990) Detection of numerical chromosomal abnormalities in neoplastic hematopoietic cells by in situ hybridization with a chromosome-specific probe Am J Pathol 136:131-139.

Arnoldus EPJ, Wiegant J, Noordermeer IA, Wessels JW, Beverstock G, Grosveld GC, van der Ploeg M, Raap AK (1990) Detection of the Philadelphia chromosome in interphase nuclei. Cytogenet Cell Genet 54:108-111.

Baldini A, Ward DC (1991) In situ hybridization banding of human chromosomes with Alu-PCR products: A simultaneous karyotype for gene mapping studies. Genomics 9:770-774.

Bornkamm GW, Kaduk B, Kachel G, Schneider U, Fresen KO, Schwa nitz G, Hermanek P (1980) Epstein-Barr virus-positive Burkitt's lymphoma in a German woman during pregnancy. Blut 40:167177.

Cremer T, Landegent J, Brückner A, Scholl HP, Schardin M, Hager HD, Devilee P, Pearson P, van der Ploeg M (1986) Detection of chromosome aberrations in the human nucleus by visualization of specific target DNAs with radioactive and nonradioactive in situ hybridization techniques: Diagnosis of trisomy 18 with probe L1.84. Hum Genet 74:346-352.

Cremer T, Lichter P, Borden J, Ward DC, Manuelidis L (1988a) Detection of chromosomal aberrations in metaphases and interphase tumor cells by in situ hybridization using chromosome-specific library probes. Hum Genet 80:235-246.

Cremer T, Remm B, Kharboush I, Jauch A, Wienberg J, Stelzer E, Cremer $C$ (1991) Non-isotopic in situ hybridization and digital image analy sis of chromosomes in mitotic and interphase cells. Revue Europeene de Technologie Biomedicale 13:50-54

Cremer T, Tesin D, Hopman AHN, Manuelidis L (1988b) Rapid inter phase and metaphase assessment of specific chromosomal changes in neuroectodermal tumor cells by in situ hybridization with chemically modified DNA probes. Exp Cell Res 176:199-220.

Crescenzi M, Seto M, Herzig GP, Weiss PD, Griffith RC, Korsmeyer SJ (1988) Thermostable DNA polymerase chain amplification of $t(14 ; 18)$ chromosome breakpoints and detection of minimal residual disease. Proc Natl Acad Sci USA 85:4869-4873.

Devilee P, Thierry RF, Kievits T, Kolluri R, Hopman AHN, Willard HF, Pearson PL, Cornelisse CJ (1988) Detection of chromosome aneuploidy in interphase nuclei from human primary breast tumors using chromosome-specific repetitive DNA probes. Cancer Res 48 . $5825-5830$.

Emmerich P, Loos P, Jauch A, Hopman AHN, Wiegant J, Higgins M, White BN, van der Ploeg M, Cremer C, Cremer T (1989) Double in situ hybridization in combination with digitized image analysis: A new approach to study interphase chromosome topography. Exp Cell Res 181:126-140.

Hartl P, Lipp M (1987) Generation of a variant $\mathrm{t}(2 ; 8)$ translocation of Burkitt's lymphoma by site-specific recombination via the $\kappa$-light chain joining signals. Mol Cell Biol 7:2037-2045.

Heim S, Mitelman F (1987) Cancer Cytogenetics. New York: Alan R. Liss, Inc.

Henglein B, Synovzik H, Groitl P, Bornkamm GW, Hartl P, Lipp M (1989) Three breakpoints of variant $\mathrm{t}(2 ; 8)$ translocations in Burkitt's lymphoma cells fall within a region 140 kilobases distal from c-myc. Mol Cell Biol 9:2105-2113

Hopman AHN, Ramaekers FCS, Raap AK, Beck JLM, Devilee P, van der Ploeg M, Vooijs GP (1988) In situ hybridization as a tool to study numerical chromosome aberration in solid bladder tumors. Histochemistry 89:307-316.

Hopman AHN, Poddighe PJ, Smeets AWGB, Moesker O, Beck ЛLM, Vooijs GP, Ramaekers FCS (1989) Detection of numerical chromosome aberrations in bladder cancer by in situ hybridization. Am J Pathol 135:1105-1117.

Klobeck HG, Combriato G, Zachau HG (1987) N segment insertion and region directed hypermutation in a kappa gene of a t(2;8) chromosomal translocation. Nucleic Acids Res 15:4877-4888.

Kolluri RV, Manuelidis L, Cremer T, Sait S, Gezer S, Raza A (1990) Detection of monosomy 7 in interphase cells of patients with myeloid disorders. Am J Hematol 33:117-122

Lee MS, Chang KS, Cabanillas F, Freireich EJ, Trujillo JM, Stass SA (1987) Detection of minimal residual cells carrying the $t(14 ; 18)$ by DNA sequence amplification. Science 237:175-178.

Lengauer C, Eckelt A, Weith A, Endlich N, Ponelies N, Lichter P, Greulich KO, Cremer T (1991a) Painting of defined chromosomal regions by in situ suppression hybridization of libraries from lasermicrodissected chromosomes. Cytogenet Cell Genet 56:27-30.

Lengauer C, Lüdecke HJ, Wienterg J, Cremer T, Horsthemke B (1991b) Comparative band mapping in primates by in situ suppression hybridization of band specific DNA microlibraries. J Hum Evol 6:67-71.

Lichter P, Cremer T, Borden J, Manuelidis L, Ward DC (1988) Delineation of individual human chromosomes in metaphase and interphase cells by in situ suppression hybridization using recombinant DNA libraries. Hum Genet 80:224-234.

Lichter P, Chang Tang CJ, Cale K, Hermanson G, Evans GA, Housman D, Ward DC (1990) High resolution mapping of human chromosome 11 by in situ hybridization with cosmid clones. Science 247:64-69.

Lichter P, Boyle AL, Cremer T, Ward DC (1991) Analysis of genes and chromosomes by non-isotopic in situ hybridization. Genet Anal Techn Appl 8:24-35.

Maniatis T, Fritsch EF, Sambrook J (eds) (1982) Molecular Cloning: A Laboratory Manual. Cold Spring Harbor, NY: Cold Spring Harbor Laboratory.

Manolov G, Manolova Y (1972) Marker band in one chromosome 14 from Burkitt's lymphoma. Nature 237:33-34.

Nederlof PM, Robinson D, Abuknesha R, Wiegant J, Hopman AHN, Tanke HJ, Raap AK (1989) Three-color fluorescence in situ hybridization for the simultaneous detection of multiple nucleic acid sequences. Cytometry 10:20-27.

Nederlof PM, van der Flier S, Wiegant J, Raap AK, Tanke HJ, Ploem JS, van der Ploeg M (1990) Multiple fluorescence in situ hybridization. Cytometry 11:126-131.

Pinkel D, Landegent J, Collins C, Fuscoe J, Segraves R, Lucas J, Gray ] (1988) Fluorescence in situ hybridization with human chromosomespecific libraries: Detection of trisomy 21 and translocation of chromosome 4. Proc Natl Acad Sci USA 85:9138-9142.

Rappold GA, Hameister H, Cremer T, Adolph S, Henglein B, Freese UK, Lenoire GM, Bornkamm GW (1984) c-myc and immunoglobulin kappa light chain constant genes are on the $8 \mathrm{q}+$ chromosome of three Burkitt's lymphoma lines with $\mathrm{t}(2 ; 8)$ translocations. EMBO J 3:2951-2955.

Tkachuk DC, Westbrook CA, Andreeff M, Donlon TA, Cleary ML, Suryanarayan K, Homge M, Redner A, Gray J, Pinkel D (1990) Detection of bcr-abl fusion in chronic myelogenous leukemia by in situ hybridization. Science 250:559-561.

Walt H, Emmerich P, Cremer T, Hofman MC, Bannwart F (1989) Supernumerary chromosome 1 in interphase nuclei of atypical germ cells in paraffin-embedded human seminiferous tubules. Lab Invest $5: 527-531$.

Wiegant J, Ried T, Nederlof PM, van der Ploeg M, Tanke HJ, Raap AK (1991) In situ hybridization with fluoresceinated DNA. Nucleic Acids Res 19:3237-3241.

Zech L, Haglund U, Nilson K, Klein G (1976) Characteristic chromosomal abnormalities in biopsies and lymphoid-cell lines from patients with Burkitt and non-Burkitt lymphomas. Int J Cancer 17:47-56. 